\title{
Update on Filariasis in villages of Menshiat Al Qanater District, Giza Governorate, Egypt
}

\section{Original Article}

\author{
Salwa MA Dahesh ${ }^{1}$, Bahaa Eldeen F Ibrahim²
}

${ }^{1}$ Malaria and Filaria Training Center, General Administration of Endemic Diseases Control of Giza, Ministry of Health and Population, Research Institute of Medical Entomology, The General Organization for Institutes and Teaching Hospitals, Ministry of Health and Population, Egypt, ${ }^{2}$ General Director of General Administration of Endemic Diseases Control of Giza, Ministry of Health and Population, Egypt

\begin{abstract}
Background: Lymphatic filariasis (LF) or elephantiasis has been identified in Egypt since ancient times. As Wuchereria bancrofti was focally endemic in Egypt, the WHO Global program to eliminate LF that was launched in 2000, included Egypt in the first group of countries having priorities. Seven villages were selected in the present study; one of them, BaniSalama village, had received eight rounds of annual mass treatment in the form of $6 \mathrm{mg} / \mathrm{kg}$ diethyl carbamazincitrate (DEC) and $400 \mathrm{mg}$ albendazole during the period from 2007 to 2014.

Objective: The present work aimed to evaluate the situation of LF in villages of Menshiat Al Qanater District, Giza Governorate where the preliminary studies done by Endemic Disease Control Administration revealed that microfilaria (Mf) positive cases were detected in that area during the last five years.

Subjects and methods: The parasitological survey was carried out in seven villages; Al Qata, Atris, BaniSalama, Abu Ghaleb, Al Hager, Abu Hadid and Wardan during July-September, 2016. Peripheral blood samples of 2,108 persons were collected nocturnally for preparing blood films to be stained by Giemsa stain. Only positive Mf individuals were tested by antigens specific test for $W$. bancrofti called Alere Filariasis Test Strip (FTS). An entomological survey including adult Culex mosquitoes inside houses of positive cases and larvae in breeding places near them was also carried out.

Results: Eleven persons (0.5 \%) were positive for Mf in Menshiat Al Qanater District; nine from Atris (81.8\%) and two from BaniSalama village (18.2\%). The parasite rate of Atris $(2.0 \%)$ was significantly different from those of the other examined villages including BaniSalama $(0.4 \%)$. Of all positive cases, $45.5 \%$ belonged significantly to age group $21-30$ years with a mean age of $24.9 \pm 13.5$. The male gender $(81.8 \%)$ was significantly higher than female gender. Two of the positive cases from BaniSalama had not received their doses at the indicated time. There was a statistically significant difference between infection rate among mass treated and untreated individuals. The highest mean of Mf density was recorded in BaniSalama village, but there was no statistical significant difference between the mean densities of Mf of BaniSalama and Atris villages. Culex pipiens and Culex univittatus were found in highly polluted irrigation drains near houses of positive cases. The endemicity of filariasis was highly focal where all positive cases of Atris village were living in the same street and two of them were brothers. The two cases of BaniSalama were also brothers living in the same house. Most of the Mf sheaths stained by Giemsa stain were pink in samples of BaniSalama and unstained in positive samples of Atris village. Both of the Mf positive individuals were positive for FTS that detects antigens specific for $W$. bancrofti but does not rule out mixed infection.

Conclusion: Prevalence of Mf infection rate in Menshiat Al Qanater was below the threshold of the global program to eliminate LF (GPELF). After eight annual mass drug administrations (MDA) with DEC and albendazole, the infection rate of BaniSalama village reduced greatly reaching $0.4 \%$, while Atris village which was not included in MDA program showed a new small focus localized in one street in the village. Molecular and phylogenetic studies are recommended for relating and differentiating between the detected $\mathrm{Mf}$.
\end{abstract}

Key Words: C. pipiens, Giza Governorate Egypt, lymphatic filariasis, microfilaria, W. bancrofti.

Received: 1 May 2017, Accepted: 28 September, 2017.

Corresponding Author: Salwa MA Dahesh, Tel. : +20-10-1678-7766, E-mail: salwamohamed970@gmail.com.

ISSN: 1687-7942, Vol. 11, No. 1, April 2018. 


\section{INTRODUCTION}

Lymphatic filariasis (LF) or elephantiasis is a disease considered as one of the major causes of disability and deformity. In turn, the economies of the countries afflicted by such disease are greatly threatened. Three tissue dwelling filarial nematodes are responsible for that disease; $W$. bancrofti is the most common followed by Brugia malayi and $B$. timori $^{[1,2]}$. The disease afflicts more than 120 million inhabitants in eighty endemic countries ${ }^{[2-4]}$. It was reported that globally 25 million of men having filariasis acquired genital disease (hydrocele is the most common) while about 15 million acquired lymphedema or elephantiasis of the leg (mostly women ${ }^{[2]}$. The disease is transmitted mainly by the bite of infective mosquitoes that carry the third stages of filarial larvae L3. Some species of Culex, Anopheles, Aedes and Mansonia are incriminated as vectors of $\mathrm{LF}^{[2,5]}$. Culex quinquefasciatus is considered the main vector of $W$. bancrofti in urban and semi-urban areas of East Africa Southeast and Southern Asia and in the Americas ${ }^{[6]}$. Anopheles spp. are the main vectors for LF in rural areas of Asia and Africa, where An. gambiae complex and An. funestus represent the most important vectors in Africa. Aedes polynesiensis is the predominant day biting vector for $W$. bancrofti in islands of the South Pacific region. Regarding $B$. malayi the nocturnally sub-periodic form is transmitted by Mansonia mosquitoes, while nocturnally periodic form is transmitted by both Anopheles and Mansonia spp. in dense swampy forest areas. The only known mosquito vector for B. timori is An. barbirostris, which also has nocturnal periodicity ${ }^{[7]}$.

In Egypt, LF has been identified since ancient times where history of Egypt is intricately correlated to presence of Nile River, which explains why LF has been endemic mainly in Delta region ${ }^{[8]}$. Archeological reports recorded a LF worm in the groin of a mummified priest called Natsef-Amun 3000 years BC during the time of Ramses $\mathrm{XI}^{[8,9]}$. The statue of Mentuhotep II also showed enlarged limbs (2000 BC).The ancient Egyptians had depicted the enlarged leg of the queen of Punt at the Terrace of Queen Hatshepsut's temple (1501-1480 B.C $)^{[10]}$. Since mid-1960s, Egypt has tried to eliminate LF by collecting baseline data on prevalence and incidence of the disease. At that time, ten endemic regions or governorates were spotted on the Egyptian filarial map where ten million people were threatened by that disease. In 1975, Ministry of Health and Population (MOHP) established the filariasis control section for identification and detection of cases. The prevalence in some areas exceeded $20 \%$. A selective treatment strategy for positive cases with DEC was implemented. The prevalence rates reduced greatly to about $10.0 \%$ while the number of endemic villages decreased from 350 to 178 villages by the late 1990s. As DEC alone was not effective for eliminating the disease and 2.5 million persons were still at risk, the
Egyptian Government took bold steps towards being one of the first countries to join the GPELF. The strategy was by repeating annual mass treatment in the form of DEC $6 \mathrm{mg} /$ $\mathrm{kg}$ plus albendazole $400 \mathrm{mg}$ for at least five rounds ${ }^{[8]}$. Mass drug administration (MDA) achieved coverage of more than $80 \%$ because of the good infrastructure of health in Egypt. Egyptian lymphatic program started in 161 villages in seven governorates, then the number increased reaching 181 in eight governorates by 2005. In 2004, 151 villages passed post-MDA5 (five rounds) evaluation, so treatment was stopped in areas where prevalence decreased below threshold recommended by WHO guide lines. Thirty villages either failed in that evaluation or did not complete the specified five MDA rounds. The evaluation was carried out for antigenaemia by immunochromatigraphic test (ICT) cards and also for microfilaraemia among children aged 6-8 years ${ }^{[11]}$. By the second quarter of 2017, Egypt is preparing to submit and finalize the LF elimination dossier, after the last Transmission Assessment Surveys (TAS3). Also, Mini-TAS in eligible six districts where environmental conditions may sustain transmission, will be carried out to include or exclude further need for MDA rounds ${ }^{[12]}$. WHO recommendations are also to sustain management of morbidity and increase activities for preventing disability in all endemic areas until filariasis does not constitute a public health problem in Egypt ${ }^{[12,13]}$. Globally estimates during the previous thirteen years revealed that more than 96 million cases were cured, while 36 million cases of lymphoma and hydrocele still remain ${ }^{[2]}$. Preliminary studies (kindly provided by Endemic Disease Control Administration) concerning prevalence of microfilaraemia revealed that Menshiate Al Qanater was the only area that recorded positive $\mathrm{Mf}$ cases in the last five years. The present work aims to evaluate the epidemiological situation of LF in villages of Menshiat Al Qanater District, Giza Governorate, Egypt, through parasitological and entomological surveys.

\section{SUBJECTS AND METHODS}

Study area: Menshiat Al Qanater is a district in Giza Governorate that includes 23 villages, covering an area of about $200 \mathrm{Km}^{2}$, with a consensus of 750,000 individuals in 2016. Its borders are Menufia Governorate to the north, Awsim District to the south, the Nile River to the east, and Kerdasa District to the west. Its GPS is $30.183314 \mathrm{~N}$ 31.109144 E. Seven villages were selected in the present work; Al Qata, Atris, BaniSalama, Abu Ghaleb, Al Hager, Abu Hadid and Wardan. Their location and GPS are demonstrated in figures $(1 \mathrm{a}, \mathrm{b})$. The prominent aspects of rural areas are irrigation canals and drains, houses composed of maximum three floors, lack of sanitation and obvious low socioeconomic status of inhabitants (Figure 2). 


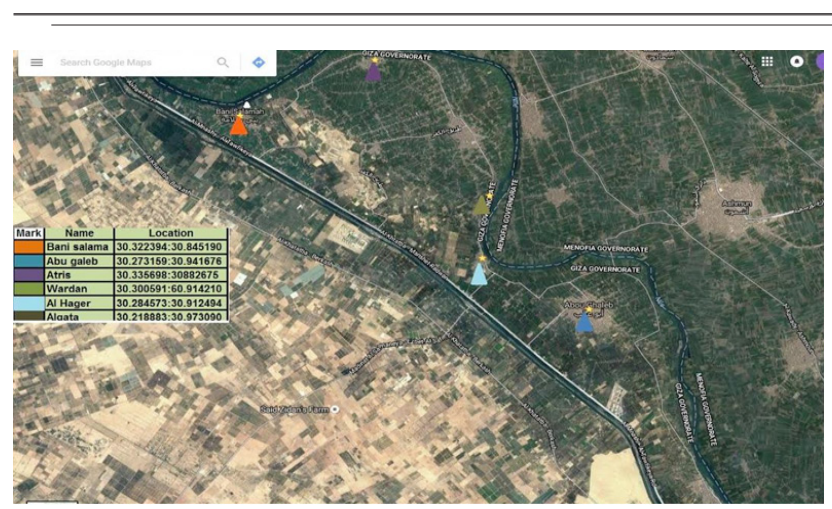

Fig. 1(a)

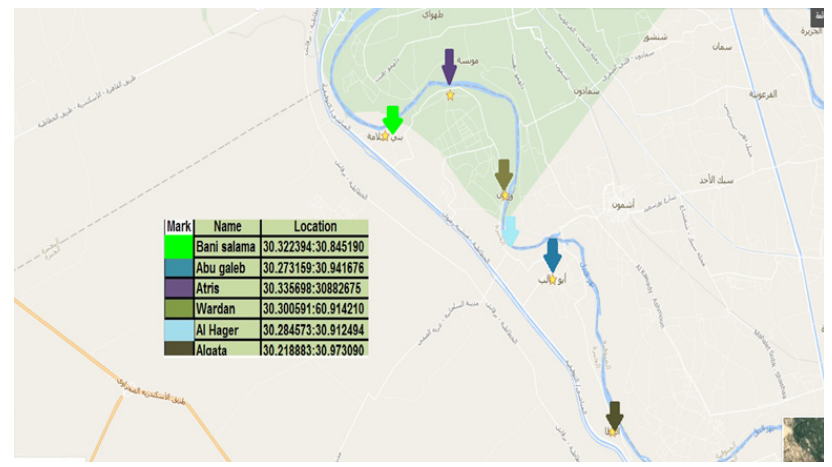

Fig. 1(b)

Fig. 1 (a, b): Map of Menshiat Al Qanater with GPS of the selected villages

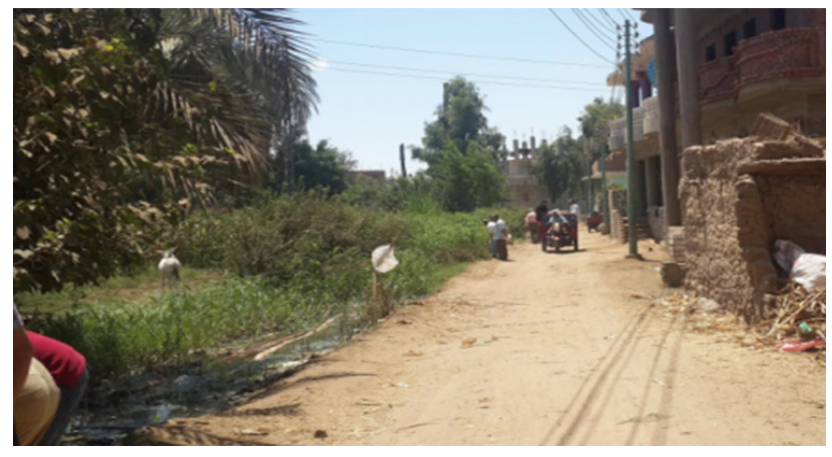

Fig. 2: The street of Atris village inhabited by nine positive cases.

Parasitological survey: Across-sectional parasitological survey was carried out in the present study to evaluate the current status of rural areas of Menshiat Al Qanater District during July-September, 2016. Randomly houseto-house visits were carried out in seven villages; Atris, BaniSalama, Al Qata, Abu Ghaleb, Al Hager, Abu Hadid and Wardan. A total of 2108 blood samples were collected at night (at $10 \mathrm{pm}$ till $2 \mathrm{am}$ ) by finger prick of individuals. Thick blood films were stained by Giemsa stain. Sampling, preparing and staining thick films were carried out by the recommended methods of $\mathrm{WHO}^{[14,15]}$. All positive cases were confirmed by repeating the test at night or by sampling after provocation as recommended by $\mathrm{WHO}^{[14]}$. The mean numbers of Mf per 20 microns blood were estimated per slide per person. From positive cases, 75 microns of whole blood were collected by finger prick for carrying out Alere Filariasis Test Strip (FTS) (California, USA) for detection of $W$. bancrofti antigens ${ }^{[16]}$.The purpose of applying FTS on samples of positive cases was to confirm that the detected Mf belonged to $W$. bancrofti species. Relevant information from individuals including personal data, type of house construction, presence of sanitation, and previous medication with MDA was recorded in a questionnaire.

Entomological survey: Houses of all positive cases were visited (nine houses) for collection of adult mosquitoes by spraying pyrethrum and application of white sheet method at early morning for detecting indoor resting densities of the vector $(\mathrm{WHO})^{[17]}$. The collected mosquitoes were identified according to a recommended key ${ }^{[18-20]}$. The abdominwal appearance of females was noted according to the simplified classification of $\mathrm{WHO}^{[17]}$. Relevant information about house construction and presence of good sanitation were recorded. The water collections around the positive cases were examined for Culex larvae. Ten dips were taken each five meters along edges of irrigation canals, drains or water bodies. The density of larvae was calculated as number of larvae per dip. The collected larvae were preserved by formalin $70 \%$ then transferred to the laboratory for identification by recommended keys ${ }^{[18-20]}$. Description of all positive breeding places was recorded.

Statistical analysis: All data were tabulated then analyzed by PC using the Epi Info and SPSS20 for Windows software packages. Regarding age of examined individuals and densities of parasites, arithmetic mean and standard deviation were used as summarized statistics. Leven test was used to test homogeneity of variances. As most variances were non-homogeneous, non-parametric statistics were carried out. Z-test was used for comparison of two proportions and replaced with Fisher's exact test when mandated by sparse data. Student's t-test was used for comparison between two arithmetic means. The MannWhitney corrected for the Z-test was used for comparison between two independent groups. The Chi-square goodness of fit test was used for comparison between distributions $^{[21,22]}$. The 0.05 cut-off value was used as a criterion for statistical significance and all statistical tests were interpreted in a two-tailed fashion.

Ethical consideration: The study was carried out after approval and supervision of the MOHP. All examined persons were healthy, educated, and agreed to contribute before sampling.

\section{RESULTS}

Parasitological survey: Only eleven persons (0.5\%) proved positive for circulating Mf in Menshiat Al Qanater; nine of them from Atris (81.8\% of total positive), while the remaining two cases $(18.2 \%)$ were from BaniSalama village. Only the parasite rate of Atris $(2.0 \%)$ showed 
highly significant difference compared to the rest of the villages (Table 1), and was also significantly higher than that of BaniSalama $(0.4 \%)$ (Table 2). The affected male gender $(81.8 \%$ of total positive) was significantly higher than female gender (18.2\% of total positive) (Table 3 ). Of all positive cases, $45.5 \%$ belonged significantly to age group 21-30 years where the mean age of positive group

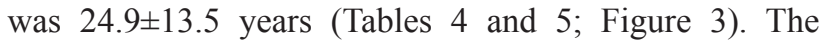
highest mean of Mf density was recorded in BaniSalama village but there was no statistical significant difference between the mean densities of Mf of BaniSalama and Atris villages (Tables 6 and 7). In Bani Salma the previous mean percent of mass treated individuals was $86.6 \%$ (Table 8 ; Figure 4). A statistically significant difference was found between the percent of mass treated examined individuals during the present study (by questionnaire) and the mean percent estimated from records kindly provided by General Administration of Endemic Diseases Control of Giza, MOHP (Table 9). The infection rate among mass treated

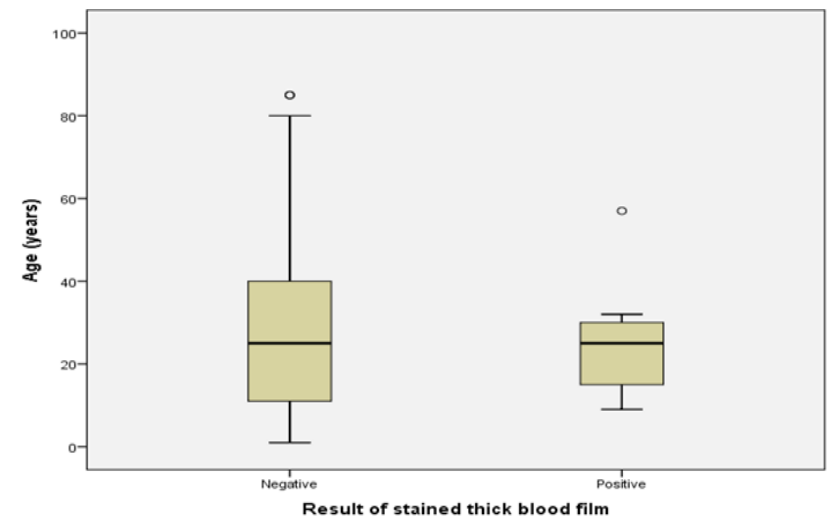

Fig. 3: Comparison between positive and negative examined individuals according to their ages

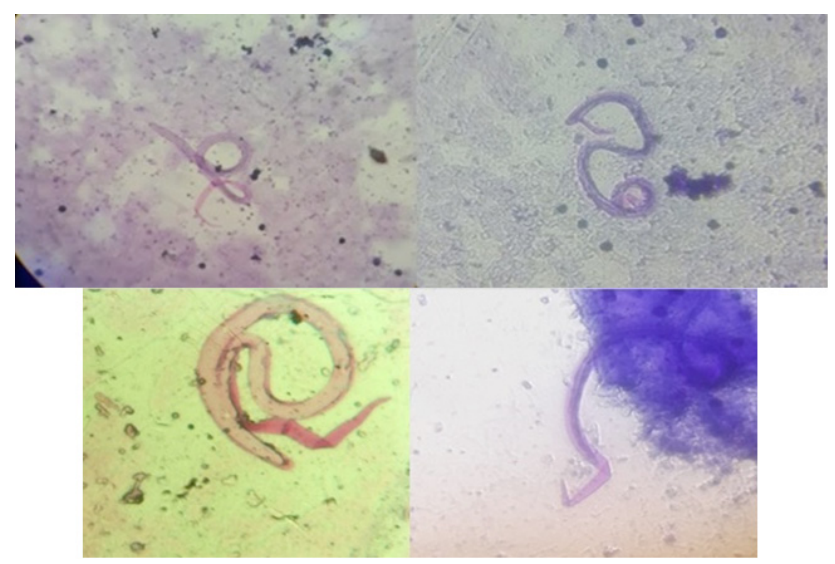

Fig. 5: Microfilaria in thick blood films stained by Giemsa showing pink colored sheaths (samples of BeniSalama village) persons was statistically significantly lower than subsample of untreated persons where all recorded positive cases had not received treatment (Table 10$)$. The majority $(70 \%)$ of the Mf sheaths stained by Giemsa were pink in samples from BaniSalama (Figure 5) while they were unstained in positive samples from Atris village (Figure 6).

Entomological survey: Identification of collected adults revealed that $C$. pipiens was the only collected species. The feeding and gravidity of $C$. pipiens females showed a higher number of fed females compared with that of gravid ones (Table 11). C. pipiens and C. univittatus larvae were found in highly polluted irrigation drains near houses of positive cases (Table 12). The endemicity of filariasis was highly focal where all positive cases of Atris village were living in the same street and two of them were brothers (Figure 2 ). The two cases of BaniSalama were also brothers living in the same house.

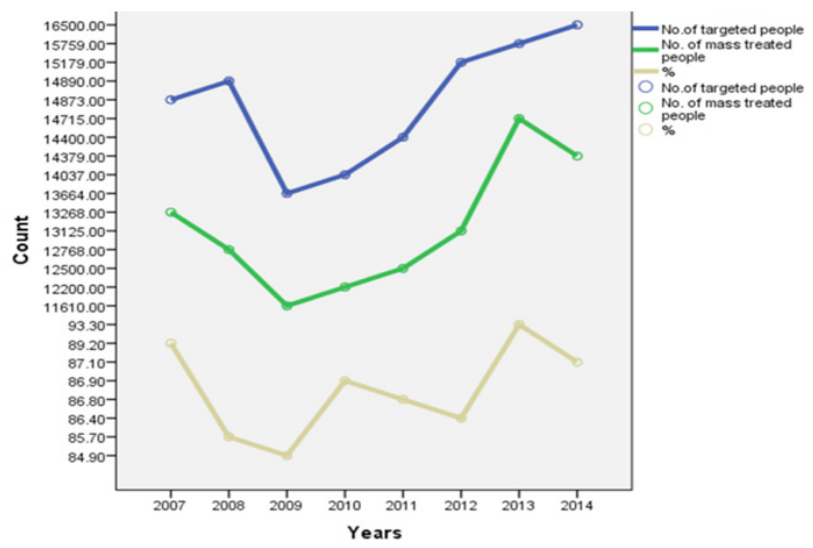

Fig. 4: Comparison between the targeted individuals and those already treated during MDA (2007-2014). (Curtsey of Endemic Disease control Administration of Giza Governorate)

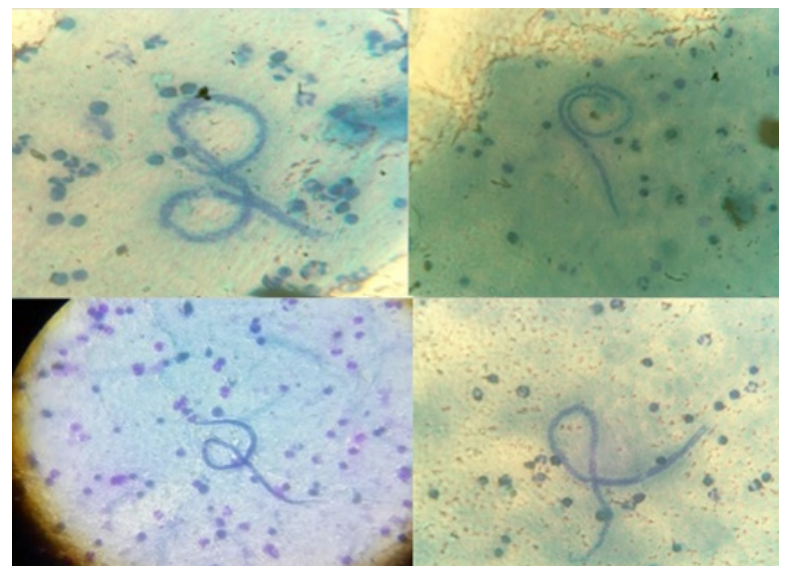

Fig. 6: Microfilaria in thick blood films stained by Giemsa showing unstained sheaths (samples of Atris village) 
Table 1: Distribution of positive filarial cases in villages of Menshiat Al Qanater

\begin{tabular}{|c|c|c|c|c|c|}
\hline \multirow{2}{*}{\multicolumn{2}{|c|}{ Village }} & & \multicolumn{2}{|c|}{ Results } & \multirow{2}{*}{ Total } \\
\hline & & & Negative & Positive & \\
\hline \multirow{2}{*}{ Al Qata } & & No. & 226 & 0 & 226 \\
\hline & & $\%$ & $100.0 \%$ & $0.0 \%$ & $100.0 \%$ \\
\hline \multirow{2}{*}{ Abu Ghaleb } & & No. & 313 & 0 & 313 \\
\hline & & $\%$ & $100.0 \%$ & $0.0 \%$ & $100.0 \%$ \\
\hline \multirow{2}{*}{ Al Hager } & & No. & 330 & 0 & 330 \\
\hline & & $\%$ & $100.0 \%$ & $0.0 \%$ & $100.0 \%$ \\
\hline \multirow{2}{*}{ Abu Hadid } & & No. & 25 & 0 & 25 \\
\hline & & $\%$ & $100.0 \%$ & $0.0 \%$ & $100.0 \%$ \\
\hline \multirow{2}{*}{ Wardan } & & No. & 303 & 0 & 303 \\
\hline & & $\%$ & $100.0 \%$ & $0.0 \%$ & $100.0 \%$ \\
\hline \multirow{2}{*}{ Atris } & & No. & 448 & $9 * *$ & 457 \\
\hline & & $\%$ & $98.0 \%$ & $2.0 \% * *$ & $100.0 \%$ \\
\hline \multirow{6}{*}{ BaniSalama } & \multirow{2}{*}{ Abu Salem } & No. & 273 & 0 & 273 \\
\hline & & $\%$ & $100.0 \%$ & $0.0 \%$ & $100.0 \%$ \\
\hline & \multirow{2}{*}{ Gad Isa } & No. & 179 & 2 & 181 \\
\hline & & $\%$ & $98.9 \%$ & $1.1 \%$ & $100.0 \%$ \\
\hline & \multirow{2}{*}{ Total } & No. & 452 & 2 & 454 \\
\hline & & $\%$ & $99.6 \%$ & $0.4 \%$ & $100.0 \%$ \\
\hline \multirow{2}{*}{ Total } & & No. & 2097 & 11 & 2108 \\
\hline & & $\%$ & $99.5 \%$ & $0.5 \%$ & $100.0 \%$ \\
\hline
\end{tabular}

Pearson chi-square=27.344 $(P<0.001)$, Likelihood ratio=27.051 $(P<0.001)$, Fisher's exact test $(P<0.05)$.**Highly statistical difference between Atris and other villages.

Table 2: Comparison between Atris and BaniSalama villages according to filarial infection rate

\begin{tabular}{|c|c|c|c|c|}
\hline Area & & Negative & Positive & Total \\
\hline \multirow{2}{*}{ Atris } & No. & 448 & 9 & 457 \\
\hline & $\%$ & $98.0 \%$ & $2.0 \%$ & $100.0 \%$ \\
\hline \multirow{2}{*}{ BaniSalama } & No. & 452 & 2 & 454 \\
\hline & $\%$ & $99.6 \%$ & $0.4 \%$ & $100.0 \%$ \\
\hline \multirow{2}{*}{ Total } & No. & 900 & 11 & 911 \\
\hline & $\%$ & $98.8 \%$ & $1.2 \%$ & $100.0 \%$ \\
\hline
\end{tabular}

Pearson chi-square=27.344 $(P<0.001)$, Likelihood ratio=27.051 $(P<0.001)$, Fisher's exact test $(P<0.001)$.

Table 3: Comparison between positive cases and subsample of negative individuals according to gender.

\begin{tabular}{|c|c|c|c|c|}
\hline \multirow{2}{*}{ Sex } & & \multicolumn{2}{|c|}{ Results } & \multirow{2}{*}{ Total } \\
\hline & & Negative & Positive & \\
\hline \multirow{2}{*}{ Male } & No. & 60 & 9 & 69 \\
\hline & $\%$ & $46.5 \%$ & $81.8 \%$ & $49.3 \%$ \\
\hline \multirow{2}{*}{ Female } & No. & 69 & 2 & 71 \\
\hline & $\%$ & $53.5 \%$ & $18.2 \%$ & $50.7 \%$ \\
\hline \multirow{2}{*}{ Total } & No. & 129 & 11 & 140 \\
\hline & $\%$ & $100.0 \%$ & $100.0 \%$ & $100.0 \%$ \\
\hline
\end{tabular}

Pearson chi-square=5.05, $P<0.05$, Likelihood ratio=5.45, $P<0.05$, Fisher's exact test $P<0.05$. 
Filariasis in some Giza villages Dahesh and Ibrahim

Table 4: Distribution of filarial cases according to different age group of all examined individuals

\begin{tabular}{|c|c|c|c|c|}
\hline \multicolumn{2}{|c|}{ Age group } & \multicolumn{2}{|c|}{ Results } & \multirow{2}{*}{ Total } \\
\hline & & Negative & Positive & \\
\hline \multirow{2}{*}{ Less than 5 years } & No. & 138 & 0 & 138 \\
\hline & $\%$ & $6.6 \%$ & $0.0 \%$ & $6.5 \%$ \\
\hline \multirow{2}{*}{5 - 10 years } & No. & 459 & 2 & 461 \\
\hline & $\%$ & $21.9 \%$ & $18.2 \%$ & $21.9 \%$ \\
\hline \multirow{2}{*}{ 11- 20 years } & No. & 326 & 2 & 328 \\
\hline & $\%$ & $15.5 \%$ & $18.2 \%$ & $15.6 \%$ \\
\hline \multirow{2}{*}{ 21-30 years } & No. & 418 & $5 * *$ & 423 \\
\hline & $\%$ & $19.9 \%$ & $45.5 \% * *$ & $20.1 \%$ \\
\hline \multirow{2}{*}{$31-40$ years } & No. & 309 & 1 & 310 \\
\hline & $\%$ & $14.7 \%$ & $9.1 \%$ & $14.7 \%$ \\
\hline \multirow{2}{*}{ 41-50 years } & No. & 182 & 0 & 182 \\
\hline & $\%$ & $8.7 \%$ & $0.0 \%$ & $8.6 \%$ \\
\hline \multirow{2}{*}{ Over 50 years } & No. & 265 & 1 & 266 \\
\hline & $\%$ & $12.6 \%$ & $9.1 \%$ & $12.6 \%$ \\
\hline \multirow{2}{*}{ Total } & No. & 2097 & 11 & 2108 \\
\hline & $\%$ & $100.0 \%$ & $100.0 \%$ & $100.0 \%$ \\
\hline
\end{tabular}

Pearson chi-square $=5.694(P>0.05)$, Likelihood ratio $=6.473(P>0.05)$, Fisher's exact test $(P>0.05) . * *$ The test was significant after adjusting $P$ - value (Bonferroni method) ${ }^{[20,21]}$.

Table 5: Comparison between age means (years) of positive and negative groups in Atris and BaniSalama villages

\begin{tabular}{lccccc}
\hline \hline Result & No. & Mean age & $\begin{array}{c}\text { Standard } \\
\text { Deviation }\end{array}$ & Standard Error & $\begin{array}{c}\text { Statistical } \\
\text { analysis }\end{array}$ \\
\hline Negative & 900 & 25.53 & 17.486 & 0.583 & $\mathrm{~T}=0.117$, \\
Positive & 11 & 24.91 & 13.561 & 4.089 & $P>0.05$ \\
\hline \hline
\end{tabular}

Table 6: The mean count of Mf, gender and age of positive cases in villages examined during July and September 2016.

\begin{tabular}{lcccc}
\hline \hline Serial No. & Village & Gender & Age & Mf mean count/20 microns blood \\
\hline 1 & Atris & Female & 57 & $2.4 \pm 5.8$ \\
2 & Atris & Male & 15 & $1.3 \pm 2.6$ \\
3 & Atris & Male & 15 & $3.2 \pm 5.1$ \\
4 & Atris & Male & 9 & $1.3 \pm 2.6$ \\
5 & Atris & Male & 9 & $1.5 \pm 2.5$ \\
6 & Atris & Female & 27 & $2.4 \pm 5.8$ \\
7 & Atris & Male & 33 & $2.4 \pm 1.5$ \\
8 & Atris & Male & 29 & $0.5 \pm 1.5$ \\
9 & Atris & Male & 25 & $0.5 \pm 1.4$ \\
10 & BaniSalama(Gad isa) & Male & 27 & $11.2 \pm 14.8$ \\
11 & BaniSalama(Gad isa) & Male & 25 & $2.0 \pm 4.4$ \\
\hline \hline
\end{tabular}

Table 7: Comparison between mean Mf densities of Atris and BaniSalama villages.

\begin{tabular}{llcccc}
\hline \hline Area & & No. & Mean rank & Sum of ranks & Statistical analysis \\
\hline \multirow{2}{*}{$\begin{array}{l}\text { MF } \\
\text { mean }\end{array}$} & Atris & 9 & 5.33 & 48.00 & Mann-Whitney \\
& BaniSalama & 2 & 9.00 & 18.00 & U $=3.0$ Wilcoxon \\
\cline { 2 - 6 } & Total & 11 & & & \\
\hline \hline
\end{tabular}


Table 8: Mass treatment with DEC and albendazole during 2007-2014 in BaniSalama village, Menshiat Al Qanater, Giza Governorate (Curtsey of Endemic Disease control Administration of Giza Governorate).

\begin{tabular}{cccc}
\hline \hline $\begin{array}{c}\text { Date of mass } \\
\text { treatment }\end{array}$ & $\begin{array}{c}\text { No. of targeted individuals } \\
\text { (above 5 years) }\end{array}$ & No. of treated people \\
\hline $\mathbf{2 0 0 7}$ & 14873 & 13268 & $89.2 \%$ \\
$\mathbf{2 0 0 8}$ & 14890 & 12768 & $85.7 \%$ \\
$\mathbf{2 0 0 9}$ & 13664 & 11610 & $84.9 \%$ \\
$\mathbf{2 0 1 0}$ & 14037 & 12200 & $86.9 \%$ \\
$\mathbf{2 0 1 1}$ & 14400 & 13125 & $86.8 \%$ \\
$\mathbf{2 0 1 2}$ & 15179 & 14715 & $86.4 \%$ \\
$\mathbf{2 0 1 3}$ & 15759 & 14379 & $93.3 \%$ \\
$\mathbf{2 0 1 4}$ & 16500 & & $87.1 \%$ \\
\hline
\end{tabular}

Table 9: Comparison between the percent of mass treated examined individuals during the present study and the mean percent estimated from records kindly provided by General Administration of Endemic Diseases Control of Giza, (MOHP).

\begin{tabular}{cccc}
\hline \hline Mass treatment & No. & $\begin{array}{c}\text { \% from questionnaire } \\
\text { in the present study }\end{array}$ & \% from MOHP \\
\hline Treated & 59 & $73.8 \%$ & $86.6 \%$ \\
Untreated & 21 & $26.2 \%$ & $P$ value $=\mathbf{0 . 0 2}$ \\
\hline Total & 80 & $100.0 \%$ & \\
\hline \hline
\end{tabular}

Table 10: Comparison between subsamples from Atris and BaniSalama villages according to filarial infection rate and previous mass treatment with DEC and albendazole during (2007- 2014).

\begin{tabular}{|c|c|c|c|c|c|}
\hline \multirow{2}{*}{ Village name } & \multirow{2}{*}{\multicolumn{2}{|c|}{ Microfilaraemia }} & \multicolumn{2}{|c|}{ Mass treatment during 2007-2014 } & \multirow{2}{*}{ Total } \\
\hline & & & No & Yes & \\
\hline \multirow{6}{*}{ Atris } & Negative & No. & 71 & 0 & 71 \\
\hline & & $\%$ & $100.0 \%$ & $0 \%$ & $100.0 \%$ \\
\hline & Positive & No. & 9 & 0 & 9 \\
\hline & & $\%$ & $100.0 \%$ & $0 \%$ & $100.0 \%$ \\
\hline & Total & No. & 80 & 0 & 80 \\
\hline & & $\%$ & $100.0 \%$ & $0 \%$ & $100.0 \%$ \\
\hline \multirow{6}{*}{ BaniSalama } & Negative & No. & 19 & 59 & 78 \\
\hline & & $\%$ & $24.4 \%$ & $75.6 \%$ & $100.0 \%$ \\
\hline & Positive & No. & 2 & 0 & 2 \\
\hline & & $\%$ & $100.0 \%$ & $0.0 \%$ & $100.0 \%$ \\
\hline & Total & No. & 21 & 59 & 80 \\
\hline & & $\%$ & $26.2 \%$ & $73.8 \%$ & $100.0 \%$ \\
\hline \multirow{6}{*}{ Total } & Negative & No. & 90 & 59 & 149 \\
\hline & & $\%$ & $60.4 \%$ & $39.6 \%$ & $100.0 \%$ \\
\hline & Positive & No. & 11 & 0 & 11 \\
\hline & & $\%$ & $100.0 \%$ & $0.0 \%$ & $100.0 \%$ \\
\hline & Total & No. & 101 & 59 & 160 \\
\hline & & $\%$ & $63.1 \%$ & $36.9 \%$ & $100.0 \%$ \\
\hline
\end{tabular}

Pearson Chi-Square=6.90, $P<0.05$, Likelihood Ratio=10.5, $P<0.001$, Fisher's Exact Test $P<0.05$. 
Filariasis in some Giza villages Dahesh and Ibrahim

Table 11: Adults of Culex pipiens collected from houses of positive filarial cases according to densities, sex, feeding and gravidity.

\begin{tabular}{|c|c|c|c|c|c|c|c|c|}
\hline \multirow{2}{*}{$\begin{array}{l}\text { House } \\
\text { No. }\end{array}$} & \multirow[t]{2}{*}{ Village } & \multicolumn{3}{|c|}{ No. of Culex pipiens } & \multicolumn{4}{|c|}{ Feeding and gravidity } \\
\hline & & M & $\mathbf{F}$ & Total & Unfed & Fed & Half gravid & Full gravid \\
\hline 1 & Atris & 0 & 4 & 4 & 0 & 2 & 2 & 0 \\
\hline 2 & Atris & 0 & 6 & 6 & 0 & 5 & 1 & 0 \\
\hline 3 & Atris & 11 & 15 & 26 & 3 & 4 & 5 & 3 \\
\hline 4 & Atris & 5 & 4 & 9 & 0 & 3 & 0 & 1 \\
\hline 5 & Atris & 0 & 4 & 4 & 0 & 1 & 2 & 1 \\
\hline 6 & Atris & 22 & 8 & 30 & 2 & 2 & 1 & 3 \\
\hline 7 & Atris & 0 & 3 & 3 & 0 & 1 & 1 & 1 \\
\hline 8* & Atris & 13 & 8 & 21 & 3 & 3 & 1 & 1 \\
\hline 9* & BaniSalama & 0 & 7 & 7 & 0 & 3 & 3 & 1 \\
\hline Total & & 51 & 59 & 110 & 8 & 24 & 16 & 11 \\
\hline
\end{tabular}

*House contained two positive cases, $\mathrm{M}=$ Male, $\mathrm{F}=$ Female.

Table 12: Description of Culex larvae breeding places located near houses of positive filarial cases

\begin{tabular}{|c|c|c|c|c|c|c|}
\hline $\begin{array}{l}\text { Serial } \\
\text { No }\end{array}$ & Village & $\begin{array}{l}* \text { Station } \\
\text { area }\end{array}$ & $\begin{array}{l}\text { Positive } \\
\text { sites }\end{array}$ & Breeding place & Larvae spp. & $\begin{array}{c}\text { Mean densities } \\
\text { of larvae } \\
\text { (No./ dip) }\end{array}$ \\
\hline 1 & Atris & $1.5 \times 10$ & 2 & Semi polluted shallow agriculture drain & C.pipiens & $120 \pm 43$ \\
\hline 2 & Atris & $1.5 \times 10$ & 2 & Semi polluted shallow agriculture drain & C.pipiens & $110 \pm 30$ \\
\hline 3 & Atris & $1.5 \times 30$ & 5 & Semi polluted shallow agriculture drain & C.pipiens & $\mathbf{7 0} \pm \mathbf{2 0}$ \\
\hline 4 & Atris & $1.5 \times 50$ & 4 & Slightly polluted shallow agriculture drain & C.pipiens & $40 \pm 15$ \\
\hline 5 & Atris & $1.0 \times 40$ & 3 & $\begin{array}{l}\text { Highly polluted shallow agriculture drain } \\
\text { containing rubbish and soap water }\end{array}$ & $\begin{array}{l}\text { C. pipiens } \\
\text { C. univittatus }\end{array}$ & $\begin{array}{l}160 \pm 60 \\
100 \pm 40\end{array}$ \\
\hline 6 & $\begin{array}{c}\text { Bani } \\
\text { Salama }\end{array}$ & $1.5 \times 60$ & 5 & $\begin{array}{l}\text { Highly polluted shallow agriculture drain } \\
\text { containing rubbish and soap water }\end{array}$ & C. pipiens & $150 \pm 60$ \\
\hline
\end{tabular}

* Station area means width X length (in meters)

\section{DISCUSSION}

Results of the present study revealed that the updated prevalence of microfilaraemia among the examined population residing in rural areas of Menshiat Al-Qanater Center was $0.5 \%$ (11/2108 examined). Most cases were from Atris village (nine cases: $81.8 \%$ ) while the remaining two cases $(18.2 \%)$ were from BaniSalama village. Parasite rate of Atris $(2.0 \%)$ was significantly different from the other villages including BaniSalama (0.4\%).

The most recent study published in 2016, covered results of samples collected between October 2012 and March 2014 in endemic areas of five governorates in Egypt. The study revealed that the total infection rate using circulating filarial antigen CFA tests was 3.3\% (10/300 samples), nine of them were residents of Giza (BaniSalama village) and one from Menoufiya Governorate (Dalhamo village). Only one case was positive for $\mathrm{Mf}^{[23]}$. Generally the prevalence of infection rates determined by detecting circulating antigenaemia of adult worm, were significantly higher than those detecting microfilaraemia in all age groups $^{[1,24]}$. In a large study conducted by Ramzy et al. determination of the effect of annual MDA with DEC and Albendazole revealed a marked reduction in $\mathrm{Mf}$ carriers with an elimination threshold of $1 \%$ in Qualiobiya governorate since there were no positive Mf cases; while microfilaraemia rate reached $1.2 \%$ in Giza governorate ${ }^{[25]}$.

Concerning gender and ages, the present study revealed that most positive cases were males $(81.8 \%)$ with no statistically significant difference between the two sexes. Significantly, $45.5 \%$ of positive cases belonged to age group 21-30 years. The difference was statistically significant after adjusting $P$ - value by Bonferroni method ${ }^{[20,21]}$. Also the mean age of positive group $(24.9 \pm 13.5)$ was lower than that of negative group $(25.5 \pm 17.4)$ but the difference was not statistically significant. The results agreed with AbdelShafi et al. who recorded a higher antigenaemia rate among male gender, and the ages of positive cases ranged from 20 to 50 years ${ }^{[23]}$. In addition, studies conducted six years after cessation of MDA in Sri Lanka revealed that the infection rate among male gender was significantly higher than that among females. It was also mentioned that the infection rate 
among age group above 30 years was statistically higher than in children. The survey was carried out by CFA test ${ }^{[26]}$. Likewise Weil et al. had recorded that microfilaraemia and antigenaemia were significantly lower in ages below 20 years in areas of the Nile Delta of Egypt ${ }^{[27]}$. Generally, in highly endemic areas as in East Africa Mf begin to appear in approximately 5-years aged children. The prevalence of infection rates increase with age to level out above 30 years and then slightly decrease in older ages ${ }^{[1,24]}$. Furthermore, it was found that microfilaraemia prevalence was significant particularly in age group 15-40 years. It was thought that there is high resistance against infection among females in reproductive age due to hormonal reproductive factors ${ }^{[1,28]}$.

Regarding the effect of annual MDA on all individuals above 4 years of age, except pregnant women, in the form of DEC with albendazole, the present study conducted a comparison between the infection rate of BaniSalama village that had received eight annual rounds of mass treatment during years from 2007 to 2014, and Atris village that had not received any antifilariasis mass treatment. The result revealed that the infection rate of BaniSalama $(0.4 \%)$ was lower than that of Atris village $(2.0 \%)$ where the difference was statistically significant. Revision of the questionnaire for positive cases and subsample of negative individuals revealed that all positive cases didn't receive mass treatment. Nine of the positive cases inhabited Atris village which was not included in MDA program while the two other cases were from BaniSalama but they had not received treatment. The two positive cases of BaniSalama were brothers living in the same house; one of them refused treatment while the other was away during the anti-filariasis campaign. All other inhabitants or family members of the two brothers had received their doses. The difference between the infection rate of individuals receiving mass treatment and those untreated was statistically significant. Results of the questionnaire also revealed that $73.8 \%$ of subsample of examined individuals had received mass treatment. According to records kindly provided by General Administration of Endemic Diseases Control of Giza, MOHP, the mean percent of people who had already received their doses, out of the targeted population, during years from 2007 to 2014 in BaniSalama village was 86.6\%. The highest coverage was $93.3 \%$ in year 2013 while the lowest percent was $84.9 \%$ in year 2009 . The difference between percentage of treatment coverage in the present study and records obtained from MOHP was statistically significant. This is probably because of the high percentage of low aged children included in the study subsample and who were not involved in the MDA program, where $6.5 \%$ and $21.9 \%$ were under 5 years and from 5-10 years, respectively. Abd Elaziz et al. conducted a large survey concerned with compliance to MDA in six areas in Egypt. Their study revealed that Giza and Delta Governorates showed high compliance to MDA (83.6\%), being higher in the male gender and older age. The lower compliance was by females due to pregnancy, as well as other adverse events ${ }^{[29]}$.
Concerning microfilaraemia densities, we found that the mean Mf density in BaniSalama village was higher than that in Atris village but the difference was not statistically significant. The highest density $(14.8 \pm 11.2$ Mf/20 microns blood) was found in a male aged 27 years inhabitant of BaniSalam avillage, while the lowest density (1.4 $\pm 0.5 \mathrm{Mf} / 20$ microns blood) was in a male aged 25 years from Atris village. BaniSalama village had joined the program from 2007 to 2014 for eight annual rounds, decreasing the prevalence to the target threshold of $1.0 \%$. The infection rate decreased reaching $0.4 \%$ achieving the goal of GPELF; while the higher density of Mf found in the sample from BaniSalama reflected the high transmission rate present before MDA program implementation, since that one person had refused medication. The lower densities of microfilaraemia in Atris village may reflect the recent involvement of that area as a focus with low transmission rate where most of stained thick blood films contained only one or two Mf/20 microns blood. Transmission in any community is influenced by microfilaraemia prevalence rate or the number of infected persons, the densities of mosquito vectors, the densities of Mf in the blood of infected cases, the efficiency of the vector towards developing the infective larvae, and the high frequent human contact with vector $^{[2]}$.

In the present study, morphology of Giemsa stained Mf in samples collected from BaniSalama varied greatly from those of Atris. Most of Mf in samples from the former locality showed pink stained sheaths, while all those in samples from the latter locality had unstained sheaths. All positive cases from the two villages gave positive results by FTS which detects antigens specific for $W$. bancrofti but does not rule out mixed infection. Bench aids of WHO illustrate that microfilarial sheaths of B. malayi stain pink by Giemsa stain, while they are unstained in case of $W$. bancrofti ${ }^{[16]}$. It is worth noting that both stained and unstained forms were identified in individuals positive by FTS. The results of FTS confirmed that Mf with unstained sheaths found in samples of Atris belonged to W. bancrofti species while in BaniSalama there are two probabilities; the two types of Mf in the samples of examined individuals belonged to $W$. bancrofti species and the morphological difference in staining is due to difference within the strains while the second probability is the presence of $W$. bancrofti species with another species other than $W$. bancrofti. If the sample had given a negative result in the presence of $\mathrm{Mf}$ that would have meant the detected Mf is not W. bancrofti while the positive result refers to the presence of Mf alone or with other species. This important observation calls for more molecular and phylogenetic studies for relating or differentiating between species or even strains having pink stained and unstained sheaths by the same stain.

Regarding the entomological studies conducted inside houses of positive cases, only adults of $C$. pipiens were collected from all houses. The abdominal appearance of females referred to the greater ratio of fed forms with 
swollen red abdomens than gravid ones with swollen pale abdomens ${ }^{[17]}$.This indicates the exophilic tendency of $C$. pipiens to rest outside of houses and also explains why most of infected cases were males. The larval survey around the houses of positive cases indicated that only two species of Culex were found; C. pipiens and C. univittatus. The highly polluted water of irrigation drains contained the highest larval densities of both species. Harbach had recorded the two species $C$. pipiens and $C$. univittatus among twenty species recognized in southwestern Asia and Egypt $^{[30]}$. C. pipiens is considered the vector of lymphatic elephantiasis in the Middle East and Egypt ${ }^{[23,31,33,34]}$, as well as Western Nile virus ${ }^{[35]}$ and Rift Valley fever virus ${ }^{[36]}$. Different densities of other Culicinae species were reported in various $\mathrm{LF}$ endemic areas in Egypt. These include $C$. perexiguus, C. antennatus, C. pusillus, C. sinaiticus, Aedes (Ochlerotatus) caspius, Aedes (Ochlerotatus) detritus and Culiseta (Allotheobaldia) longiareolata ${ }^{[37,38]}$. Abdel-Shafi et al. recorded three species of mosquitoes in BaniSalama, Giza and in the Delta; C. pipiens being the most prominent species $(85.7 \%)$ followed by $C$. pusillus and $C$. quinquefasciatus ${ }^{[39]}$. Many obstacles faced vector control by using chemical insecticides, as the development of resistance against most of insecticides as well as the issue of environmental pollution and hazards for human and living animals ${ }^{[40]}$. Natural harmless compounds as abamictin, Bacillus (B) thuringiensis and spinosad were recommended for biological control because of their potent effect on Culex spp. larva $\mathrm{e}^{[41]}$. Ivermectin (abamictin) is a mixture of avermectin B1a and B2b produced by bacteria called Streptamyces avermitilis ${ }^{[42]}$. Ivermectin showed microfilaricidal activity ${ }^{[43]}$, causing interruption of transmission and effective treatment of filariasis ${ }^{[44]}$.

Concerning environmental aspects influencing filariasis transmission in Menshiat Al-Qanater, apparently the bad sanitation and common presence near houses of breeding places of $C$. pipiens, mostly as irrigation drains full of garbage, were very common. The transmission seemed to be highly focal where all cases detected in Atris village were localized in one street in the village; moreover two of the cases were brothers living in the same house. Also the two cases in BaniSalama village were brothers in the same house. These observations agree with records indicating that the distribution and transmission of filariasis were highly focal in Egypt ${ }^{[45,46]}$. It is apparent that the recorded variation in infection and transmission rates occurs in different sectors inside the same community and even from one household to the next ${ }^{[47]}$. Farid et al. carried out a large scale study for molecular xeno-monitoring of L3 in mosquitoes from Giza and Qualioubiya. Results showed that parasite DNA rates in C. pipiens were greatly reduced to $<1 \%$ after 5 rounds of MDA. The authors concluded that the parasite burden has decreased to ultra-low levels, and that larger sample sizes of mosquitoes should be collected to detect the presence of infection with L3 or even the exposure $^{[48]}$. Later on, Abdel-Shafi et al. did not detect DNA of $W$. bancrofti in the three species of Culex collected from Giza and Qualioubiya in a program for elimination of filariasi ${ }^{[39]}$. Transmission in a community is influenced by prevalence rate, the density of $\mathrm{Mf}$ in the blood of infected persons, and the density of vector mosquitoes. It was noted that the capacity of the vector affects development of infective larvae and frequency of human-vector contact ${ }^{[2,49]}$. Low socioeconomic status, highly polluted fresh water, increased use of water with absence of proper human excreta disposal and presence of pit latrines favor breeding of $C$. pipiens and have led to flaring up of transmission in such areas ${ }^{[7,50]}$.

In conclusion, Mf prevalence infection rate in Menshiat AlQanater was less than the threshold of GPELF. After eight annual MDA with DEC and Albendazole the infection rate of BaniSalama village reduced greatly reaching $0.4 \%$, while Atris village which was not included in MDA program showed a new small focus localized in one street in the village. $C$. pipiens was the most prominent species in houses of cases and in irrigation drains near them. The recorded difference in the uptake of the stain by microfilarial sheaths between Atris and BaniSalama villages requires more molecular and phylogenetic studies for relating and differentiating between them.

Acknowledgment: The authors would like to thank Dr. Ayat Haggag, Under Secretary of Endemic Diseases Control, Ministry of Health and Population, Dr Mohamed Atef, General Director of the General Administration of Malaria and Filaria, and also all members in the Ministry of Health and Population, and Malaria and Filaria Training Center for facilitating the study. Special thanks and appreciation are for Prof. Dr. Reda Ramzy the God father of filariasis in Egypt, for his valuable advices and amazing motivation.

Authors contribution: SMAD contributed to all parts of the work; BFI supervised sampling process and facilitated all managerial needs for accomplishing the work.

\section{REFERENCES}

1. Simonsen PE, Fischer P, Hoerauf A,Weil GJ. The filariasis in Manson"s Tropical Diseases. 23rd Edition. 2014; 737-765.

2. WHO. Lymphatic filariasis, Epidemiology, 2017.

3. Foo PK, Tarozzi A, Mahajan A, Yoong J, Krishnan L, Kopf D et al. High prevalence of Wuchereria bancrofti infection as detected by immunochromatographic card testing in five district of Orissa, India, previously considered to be non-endemic. Trans R Soc Trop Med Hyg 2011; 105: 109-114.

4. Melrose WD. Lymphatic filariasis: New insights into an old disease. Int J Parasitol 2002; 32: 947-960. 
5. WHO. Global programme to eliminate lymphatic filariasis: progress report for 2012. Epidemiol Rec 2013; 88: 389-399.

6. Bockarie MJ, Pedersen EM, White GB, Michael E. Role of vector control in the global programto eliminate lymphatic filariasis. Annu Rev Entomol 2009; 54: 469-487.

7. Fischer P, Supali T, Maizels RM. Lymphatic filariasis and Brugia timori: prospects for elimination. Trends Parasitol 2004; 20: 351-355.

8. WHO. The Global Elimination of Lymphatic Filariasis: The Story of Egypt. 2003

9. Ottesen EA, Duke BOL, Karam M, Behbehani K: Strategies and tools for the control/elimination of lymphatic filariasis. Bull World Health Organ 1997; 75: 491-503.

10. Otsuji Y. History, epidemiology and control of filariasis. Trop Med Health 2011; 39(Suppl 2): 3-13.

11. WHO. Eighth meeting of the Regional Programme Review Group on elimination of lymphatic filariasis. 2009.

12. WHO. Fifteenth meeting of the Regional Program Review Group on lymphatic filariasis elimination and other preventive chemotherapy programs. Amman, Jordan. October 2016; 18-20

13. WHO. Validation of elimination of lymphatic filariasis as a public health problem. 2017; ISBN 978-92-4$151195-7$

14. WHO. Monitoring and epidemiological assessment of mass drug administration for eliminating lymphatic filariasis: a manual for national elimination programs. Geneva: World Health Organization $2011 \quad$ (http://apps.who.int/iris/ bitstream/10665/44580/1/9789241501484_eng.pdf, accessed January 2017).

15. WHO. Lymphatic filariasis, diagnosis: diagnostic tests recommended for use in the Global Program to Eliminate Lymphatic Filariasis. 2017.

16. WHO. Bench aids for the diagnosis of filarial infections. 1997.

17. WHO. Manual on practical Entomology in malaria WHO division of malaria and other parasitic disease. Part II Methods and Techniques, Geneva1 975.

18. Kirkpatrick TW. Mosquitoes of Egypt. Cairo Government Press, 1925.
19. Ribeiro H, Ramos HC. Identification keys of the mosquitoes (Diptera: Cuilicidae) of Continental Portugal, Acores and Madeira. Euro Mosq Bull 1999; 3: $1-32$.

20. Azari-Hamidian S, Harbach RE. Keys to the adult females and fourth instar larvae of the mosquitoes of Iran (Diptera: Culicidae). Zootaxa (Magnolia Press 2078) 2009: 1-33

21. Lehmann E. Non-parametric statistical method based on ranks 1st ed. San Francisco: Holden-Day, 1975.

22. Altman D. Practical statistics for medical research. 1st ed. London: Chapman \& Hall. 1992.

23. Abdel-Shafi IR, Shoeib EY, Attia SS, Rubio JM, ElBadry AA. Wuchereria bancrofti microfilariae and quantitative selected circulating antigens detection in selected endemic areas in Egypt. Kasr Al Ainy Med J 2016; 22: 34-40.

24. Meyrowitsch DW, Simonsen PE, Magesa SM. A 26-year follow-up of bancroftian filariasis in two communities in north-eastern Tanzania. Ann Trop Med Parasitol 2004; 98: 155-169.

25. Ramzi RMR, ElSetouhyM, Helmy H, Ahmed ES, AbdAlaziz KM, Farid HA et al. Effect of yearly mass drug administration with diethylcarbamazine and albendazole on bancroftian filariasis in Egypt: a comprehensive assessment. Lancet 2006; 367(9515): 992-999.

26. Rao RU, Nagodavithana KC, Samarasekera SD, Wijegunawardana AD, Premakumara WDY, Perera SN et al. A comprehensive assessment of lymphatic filariasis in Sri Lanka six years after cessation of Mass Drug Administration. PLoS Negl Trop Dis 2014; 8(11): 1-13.

27. Weil GJ, Ramzy RM, El Setouhy M, Kandil AM, Ahmed ES, Faris RA. Longitudinal study of bancroftian filariasis in the Nile Delta of Egypt: baseline data and one-year follow-up. Am J Trop Med Hyg 1999; 61(1): 53-58.

28. Alexander ND, Grenfell BT. The effect of pregnancy on Wuchereria bancrofti microfilarial load in humans. Parasitol 1999; 119(2): 151-156.

29. Abd Elaziz KM1, El-Setouhy M, Bradley MH, Ramzy RM, Weil GJ. Knowledge and practice related to compliance with mass drug administration during the Egyptian national filariasis elimination program. Am J Trop Med Hyg 2013; 89(2): 260264. 
30. Harbach RE. The mosquitoes of the subgenus Culex in southwestern Asia and Egypt (Diptera: Culicidae). Contributions of the American Entomological Institute 1988; 24: 240-241.

31. Gad AM, Hammad RE, Farid HA. Uptake and development of Wuchereria bancrofti in Culex pipiens and Aedes caspius Pallas. J Egypt Soc Parasitol 1996; 26(2): 305-314.

32. Farid, HA, Hammad, RE, Kamal, SA, Christensen, BM. Selection of a strain of Culex pipiens highly susceptible to Wuchereria bancrofti. Egypt J Biol 2000; 2 : 125-131

33. Kaliwal MB, Kumar A, Shanbhag AB, Dash AP, Javali SB. Spatio-temporal variations in adult density, abdominal status and indoor resting pattern of Culex quinquefasciatus Say in Panaji, Goa, India. Indian J Med Res 2010; 131: 711-719.

34. Service M. Medical Entomology for students. 5th edition. Cambridge University press 2012; 67-78

35. El-Bahnasawy MM, Khater MMKh, Morsy TA. The mosquito borne west Nile virus infection: Is it threatening to Egypt or a neglected endemic disease? J Egypt Soc Parasitol 2013; 43(1): 87-102.

36. Darwish M, Hoogstraal H. Arboviruses infesting human and lower animals in Egypt: A review of thirty years of research. J Egypt Pub Hlth Assoc1981; 56: $1-112$.

37. El-Nagga A, Elbanna SM, Abo-Ghalia A. The impact of some environmental factors on the abundance of mosquitoes larvae in certain localities of Sharkia Governorate in Egypt. Egypt Acad J Biol Sci 2013: 6(2): 49-60.

38. Dyab AK, Galal LA, Mahmoud AES, Mokhtar Y. Xeno-monitoring of different filarial nematodes using single and multiplex PCR in mosquitoes from Assiut Governorate, Egypt. Korean J Parasitol 2015; 53(1): 77-83.

39. Abdel-Shafi IR, Shoeib EY, Attia SS, Rubio JM, Eldmardash Y, El-Badry AA. Mosquito identification and molecular xenomonitoring of lymphatic filariasis in selected endemic areas in Giza and Qualioubiya Governorates, Egypt. J Egypt Soc Parasitol 2016; 46(1): $93-100$.

40. Krishnamoorthy K, Rajendran R, Sunish IP, Reuben $\mathrm{R}$. Cost- effectiveness of the use of vector control and mass drug administration, separately or in combination, against lymphatic filariasis. Ann Trop Parasitol 2002; 96(2): 77-90.
41. El Sobky MM, Ismail HIH, Assar AA. Histochemical effects of some biological agents on Culex pipiens. J Egypt Soc Parasitol 2016; 46(1): 81- 92

42. Brewer BN, Armbrust KL, Mead KT, Holmes WE. Determination of abamectin in soil samples using high-performance liquid chromatography with tandem mass spectrometry. Rapid Commun Mass Spect 2004; 18(15): 1693-1696

43. Richards FOJ, Pam DD, Kal A, Gerlong GY, Onyeka J, Sambo Y, et al. Significant decrease in the prevalence of Wuchereria bancrofti infection in anopheline mosquitoes following the addition of albendazole to annual, ivermectin-based mass treatment in Nigeria. Ann Trop Med Parasitol 2005; 99(2): 155-64.

44. Ramaiah KD, Das PK, Vanamail P, Pani SP. The impact of six rounds of single dose mass administration of diethylcarbamazine or ivermectin on the transmission of Wuchereria bancrofti by Culex quinquefasciatus and its implications for lymphatic filariasis elimination programs. Trop Med Int Hlth 2003; 8(12): 1082-1092.

45. Khalil M. Filariasis and elephantiasis in Rosetta and the means of their effective control. J Egypt Med Assoc 1936; 19: 701-716.

46. Khalil M. The role of Arabic countries and Egypt in the discovery of elephantiasis and filariasis. J Egypt Med Assoc 1939; 22: 86-106.

47. Rwegoshora RT, Simonsen PE, Meyrowitsch DW, Malecela-Lazaro MN, Michael E, Pedersen EM. Bancroftian filariasis: house-to-house variation in the vectors and transmission - and the relationship to human infection - in an endemic community of coastal Tanzania. Ann Trop Med Parasitol 2007; 101: 51-60.

48. Farid HA, Morsy ZS, Helmy H, Ramzy RMR, El Setouhy M,Weil GJ. A critical appraisal of molecular xeno-monitoring as a tool for assessing progress toward elimination of lymphatic filariasis. Am J Trop Med Hyg 2007; 77(4): 593-600.

49. Simonsen PE, Meyrowitsch DW, Jaoko WG, Malecela MN, Mukoko D, Pedersen EM et al. Bancroftian filariasis infection, disease and specific antibody response patterns in a high and a low endemicity community in East Africa. Am J Trop Med Hyg 2002; 66: $550-559$.

50. Abou-El-Naga IF. Demographic, socioeconomic and environmental changes affecting circulation of neglected tropical diseases in Egypt. Asian Pac J Trop Med 2015; 8(11): 881-888. 